\title{
ENDOGENOUS TIME PREFERENCE AND PUBLIC POLICY: GROWTH AND FISCAL IMPLICATIONS
}

\author{
Evangelos V. Dioikitopoulos \\ University of Cyprus
}

SARANTIS KaLYVitis

Athens University of Economics and Business

This paper studies the growth and fiscal policy implications of the assumption that public policy generates an externality in the individual rate of time preference through the aggregate public capital stock. We examine the competitive equilibrium properties and we solve for endogenous growth-maximizing fiscal policy. We investigate the behavior of the government size and the growth rate to the sensitivity of time preference to public capital and the magnitude of public capital externality on production. We find that the Barro taxation rule [Barro, Robert J., Journal of Political Economy 98 (1990), 103-125], which states that the elasticity of public capital in the production function should equal the government size, is suboptimal. We show that the government does not necessarily have to increase income taxation following a rise in public capital intensity because of the externality of public capital on time preference and, in turn, on growth and the tax base of the economy.

Keywords: Endogenous Time Preference, Public Capital Externalities, Growth-Maximizing Fiscal Policies

\section{INTRODUCTION}

Can the patience of agents in an economy be determined by public policy? Casual empiricism and microeconomic evidence suggest that schooling and health, which are mainly provided by the public sector, strongly affect patience by rendering agents less impulsive to choices that tend to over-weight rewards in close temporal proximity. Lawrance (1991) found that nonwhite families without a college education have time preference rates that are about seven percentage points higher than those of white families. Similarly, Harrison et al. (2002) showed for a

We have benefited from comments and suggestions on earlier versions of the paper by C. Arkolakis, C. Azariadis, G. Economides, P. Koundouri, L. Marattint, T. Palivos, A. Philippopoulos, E. Vella, R. Wendner, A. Xepapadeas, two anonymous referees, and seminar participants at the PGPPE 2009 Workshop in Graz and the Athens University of Economics and Business. The usual disclaimer applies. Address correspondence to: Evangelos V. Dioikitopoulos, Department of Economics, University of Cyprus, P.O. Box 20537, CY-1678 Nicosia, Cyprus; e-mail: evangelos.dioikitopoulos@aueb.gr. 
sample of Danish households that highly educated adults have subjective discount rates that are roughly two-thirds those of adults who are less educated. Bauer and Chytilova (2010) report that an additional year of schooling in Ugandan villages lowered the discount rate significantly. ${ }^{1}$ In this vein, Becker and Mulligan (1997) emphasized that expenditures on "future-oriented capital," like health and education, focus agents' attention to the future, and they thus tend to be more patient and increase savings. This point goes back to Strotz (1956), who had noticed that discount functions are formed by teaching and social environment. A prominent illustration of this argument concerns the causes of the high savings rate observed in Japan during the past few decades, attributed by Horioka (1990) and Sheldon $(1997,1998)$ to, among other factors, an array of public policies implemented through educational programs that promoted the virtues of patience and thrift. ${ }^{2}$ In the present paper, we assume that the publicly provided productive input (public capital in the form of education or health) reduces the subjective discount rate and we show that the growth-maximizing Barro (1990) taxation rule, which states that the output elasticity of public capital should equal the government size, is altered. The government size does not necessarily have to increase following a rise in public capital intensity because of the external effect of public capital on time preference and, in turn, on growth and the tax base of the economy.

Up to now, several studies have analyzed the implications of endogenous time preference for the macroeconomy. Uzawa (1968), Obstfeld (1990), Shin and Epstein (1993), Drugeon (1996, 2000), Palivos et al. (1997), Stern (2006), and Chen (2007) have investigated the effects of individual decisions on the time preference rate. These authors have shown that the endogeneity of time preference is crucial for the dynamics of the economy, the existence of long-run growth, the long-run distribution of capital, and the analysis of income divergence between countries. Epstein and Hynes (1983) and Meng (2006) have endogenized the rate of time preference as a function of the aggregate macroeconomic environment, captured by aggregate consumption and income, in many variants of exogenous and endogenous growth models.

Yet little is known about the growth implications of fiscal policy when time preference is endogenously determined by public policies. In the present study, we introduce the assumption that individual patience is affected by the levels of aggregate consumption and public capital into an otherwise standard general equilibrium framework in order to assess the impact of growth-maximizing fiscal policy. To this end, we first analyze the steady-state properties of the model under the assumption of endogenous impatience as a result of public policy and we solve for endogenous growth-maximizing fiscal policy. Following Turnovsky (2000), the government sustains output growth by setting expenditures on public policy as a constant output share that is financed by a tax rate on individual output (government size). We show that the optimal government size in a secondbest growth-maximizing environment depends not only on the technological parameters of the economy, but also on the endogeneity of time preference. This 
changes the growth-maximizing rule presented by, among others, Barro (1990), Futagami et al. (1993), and Glomm and Ravikumar (1997), which states that the government share in output should equal the elasticity of public capital in the production function. In particular, the marginal cost of government revenues decreases due to the positive external effect of public capital on the rate of time preference and growth. Our comparative statics exercises regarding standard parameters of growth theory then show how the optimal government size and the growth rate can differ according to the magnitude of the response of time preference to changes in public capital.

Our findings have some novel policy implications for economic performance, as active public policies in sectors such as health and education are considered crucial in boosting growth. Standard analysis with exogenous time preference has indicated that an increase in public capital intensity increases the allocation of resources to public capital and raises the marginal cost of taxation and thus the optimal government size [Barro (1990)]. However, under the additional external effect of public policies on time preference, the effect on government size depends on the level of public capital intensity and the sensitivity of time preference. Specifically, we show that when the sensitivity of time preference is high the government, following a rise in public capital intensity, may lower rather than raise taxation in order to maximize growth. This happens because of the positive external effect on growth and the tax base, which outweighs the associated marginal cost of taxation.

The rest of the paper is structured as follows. Section 2 sets up and solves the optimization problem for households and firms and studies the steady-state properties of the decentralized economy. Section 3 analyzes the role of growthmaximizing fiscal policy, and Section 4 concludes the paper.

\section{THE COMPETITIVE DECENTRALIZED EQUILIBRIUM}

\subsection{The Basic Model}

Consider an economy with a large and constant number of infinitely lived agents, normalized to unity, that consume a single good. Each household seeks to maximize intertemporal discounted utility, given by

$$
\int_{0}^{\infty} u\left(c_{t}\right) \exp \left[-\int_{0}^{t} \rho\left(C_{v}, K_{g, v}\right) d v\right] d t
$$

with instantaneous utility function $u\left(c_{t}\right)=\ln \left(c_{t}\right)$, subject to the initial asset endowment $A(0)>0$ and the income resource constraint ${ }^{3}$

$$
\dot{A}=r A+w l-c,
$$

where $A$ denotes household financial assets, $c$ denotes individual consumption, $l$ denotes inelastic labor supply, and $r$ and $w$ denote the market interest rate 
and the wage rate, respectively. The formulation of intertemporal utility in (1) follows Meng (2006) and implies that the subjective discount rate, $\rho(\cdot, \cdot)$, is not a positive constant, as in standard growth theory, but is endogenously determined and depends on the economywide average level of consumption, $C_{v}$, and the average public capital stock, $K_{g, v}$, at time $v$.

We assume that the time preference function has the following properties:

Assumption 1. $\rho\left(C, K_{g}\right) \geq \check{\rho}>0$.

Assumption 2. $\rho_{C}^{\prime} \geq 0$ and $\rho_{K_{g}}^{\prime} \leq 0$.

Assumption 3. $\rho\left(C, K_{g}\right)=\rho\left(C / K_{g}\right)$.

Assumption 1 shows that the rate of time preference is strictly positive, implying that there exists a lower bound denoted by $\check{\rho}$. By Assumption 2, the rate of time preference depends positively on the level of aggregate consumption and negatively on the level of aggregate public capital. ${ }^{4}$ As in the rest of the literature with endogenous time preference, we assume that as agents consume more, the value of current consumption increases. We additionally assume that the higher the public capital stock in the economy, the more patient is the agent and the more willing to forego current consumption. ${ }^{5}$ Last, Assumption 3 implies homogeneity of the rate of time preference to the ratio of consumption to public capital stock, which is required for the rate of time preference to be bounded at the steady state [Palivos et al. (1997); Meng (2006)] and for the utility function to be consistent with balanced growth [Dolmas (1996)].

Notice that because these assumptions generally imply a variable time preference rate, they should be accompanied by a commitment technology. As is well known [Laibson (1997)], the optimality condition for the consumer will not hold under, say, hyperbolic discounting because the household has to figure out how consumption setting at time $t$ will alter its capital stock and hence future consumption choices. Barro (1999) has shown that a time-varying discount rate can be incorporated into the standard Ramsey model with logarithmic utility even without commitment. ${ }^{6}$

On the supply side of the economy we assume the existence of a continuum of perfectly competitive homogeneous firms, normalized to unity, that seek to maximize profits. Each firm $i$ uses private capital, $K_{i}$, and labor, $L_{i}$, with the following production technology:

$$
Y_{i}=K_{i}^{a}\left(\frac{K_{g}}{L} L_{i}\right)^{1-a}
$$

where $0<a<1$ denotes the share of private capital in the production function, $L$ denotes the aggregate labor force, $Y_{i}$ denotes individual output, and $K_{g}$ denotes the public capital stock that affects positively the productivity of labor. The firstorder conditions of the firms' profit maximization problem are given by $r=$ $(1-g) a\left(K_{i} / K_{g} L_{i}\right)^{a-1}-\delta_{k}$ and $w=(1-g)(1-a)\left(K_{i} / L_{i}\right)^{a} K_{g}^{1-a}$ and state 
that the marginal productivity of capital and labor have to equal the respective factor prices. As can readily be seen, the public capital stock, introduced here in the form of health and education expenditures, affects the marginal productivity of labor positively [Glomm and Ravikumar (1997, 1998); Strauss and Thomas (1998)].

The laws of motion for the private and public capital stocks are given by

$$
\begin{gathered}
\dot{K}_{i}=I_{i}-\delta_{K} K_{i} \\
\dot{K}_{g}=G-\delta_{g} K_{g},
\end{gathered}
$$

where $I_{i}$ and $\delta_{K}$ denote private investment and the private capital depreciation rate, and $G$ and $\delta_{g}$ denote public expenditures and the public capital depreciation rate, respectively. Following Turnovsky (2000), we assume that the government sets its expenditures as a fixed fraction of output, $g$,

$$
G=g Y,
$$

in order to sustain ongoing growth by maintaining a balance between the rate of public investment and the size of the economy. Hence, an expansion of government expenditures is parameterized by an increase in the chosen policy parameter, $g$.

\subsection{Balanced Growth}

We can now define the competitive decentralized equilibrium (CDE) of the economy in order to analyze its properties.

DEFINITION 1. The CDE of the economy is defined for the exogenous policy instrument, $g$, factor prices $r, w$, and aggregate allocations $K, K_{g}, L, C$, such that

(i) Individuals solve their intertemporal utility maximization problem by choosing $c$ and $A$, given $g$ and factor prices.

(ii) Firms choose $L_{i}$ and $K_{i}$ in order to maximize their profits, given factor prices and aggregate allocations.

(iii) All markets clear and in the capital market we have that total assets hold by the agents have to be equal to the total capital stock in the economy, $A \int_{0}^{1} L_{i}=\int_{0}^{1} K_{i}$.

(iv) The government budget constraint holds.

The CDE is then defined by (i)-(iii) under the aggregation conditions $\int_{0}^{1} K_{i}=$ $K, \int_{0}^{1} L_{i}=L$.

The growth rate of per capita consumption, $c$, in the CDE is given by

$$
\frac{\dot{c}}{c}=\left[r-\rho\left(\frac{C}{K_{g}}\right)\right] .
$$

Using the equilibrium conditions for homogeneous and symmetric firms $L_{i}=L$ and $K_{i}=K$, and assuming for the rest of the paper without loss of generality 
that $\delta_{K}=\delta_{K_{g}}=\delta$, the equilibrium growth rates of aggregate consumption and aggregate private and public capital stocks are given by the following system of equations:

$$
\begin{gathered}
\frac{\dot{C}}{C}=a(1-g)\left(\frac{K}{K_{g}}\right)^{a-1}-\rho\left(\frac{C}{K_{g}}\right)-\delta, \\
\frac{\dot{K}}{K}=(1-g)\left(\frac{K}{K_{g}}\right)^{a-1}-\frac{C}{K}-\delta, \\
\frac{\dot{K}_{g}}{K_{g}}=g\left(\frac{K}{K_{g}}\right)^{a}-\delta .
\end{gathered}
$$

Equations (8)-(10) summarize the dynamics of our economy. The transversality condition for this problem is given by

$$
\lim _{t \rightarrow \infty} \frac{K(t)}{C(t)} e^{-\rho\left(C(t) / K_{g}(t)\right) t}=0 .
$$

On the balanced growth path (BGP) consumption, private capital, and public capital grow at the same rate, $\dot{C} / C=\dot{K} / K=\dot{K}_{g} / K_{g}=\phi^{\mathrm{CDE}}{ }^{7}$ To derive the equilibrium growth rate of the economy we first define the auxiliary stationary variables $\omega \equiv C / K$ and $z \equiv K / K_{g}$. It is straightforward to show that the dynamics of (8)-(10) is equivalent to the dynamics of the following system of equations:

$$
\begin{gathered}
\frac{\dot{\omega}}{\omega}=(a-1)(1-g) z^{a-1}+\omega-\rho(z \omega), \\
\frac{\dot{z}}{z}=(1-g) z^{a-1}-\omega-g z^{a} .
\end{gathered}
$$

We can now determine the properties (existence and uniqueness) of the BGP on which $\dot{\omega} / \omega=\dot{z} / z=0$. In the Appendix we show that the BGP of the economy is unique and, for given parameter values and policy instruments, is given by

$$
\phi^{\mathrm{CDE}}=g(\bar{z})^{a}-\delta,
$$

provided that there exists $\bar{z}>0: \Phi(\bar{z})=a(1-g) \bar{z}^{a-1}-g \bar{z}^{a}-\rho(\bar{z} \cdot \bar{\omega}(\bar{z}))=0$ and $\bar{\omega}(\bar{z})=(1-g) \bar{z}^{a-1}-g \bar{z}^{a}>0$, where $\bar{\omega}$ and $\bar{z}$ are the steady-state values of $\omega$ and $z$, respectively.

In the next section we analyze growth-maximizing fiscal policy rules when the rate of time preference depends on public policy. 


\section{GROWTH-MAXIMIZING FISCAL POLICY}

In this section we endogenize public policy as summarized by the government size. By choosing policy given the CDE conditions, the government controls for externalities and raises funds accordingly to finance public policy. We focus here on second-best growth-maximizing policy, as modern growth theory has shown particular interest in growth-enhancing policies, in order to identify the relative merits and synergies of government interventions in areas such as the formation and allocation of public capital. Moreover, the growth rate is usually the main measurable objective of the government and hence it is useful to assess the contribution of the components of public capital expenditures aiming at long-run growth [Devarajan et al. (1996)]. ${ }^{8}$

DEFINITION 2. A growth-maximizing allocation in the CDE is given under Definition 1 when ( $i$ ) the government acts as a Stackelberg player and chooses $g$ in order to maximize the long-run growth rate of the economy by taking into account the aggregate maximizing behavior of the competitive equilibrium, and (ii) the government budget constraints and the feasibility and technological conditions are met.

The government seeks to maximize the growth rate of the economy, $\phi$, given by

$$
\max _{g, z} \phi=g z^{a}-\delta
$$

subject to the equilibrium CDE response summarized by $a(1-g) z^{a-1}-g z^{a}-$ $\rho(\omega(z) z)=0$ and $\omega(z)=(1-g) z^{a-1}-g z^{a}$.

The first-order conditions with respect to $z$ and $g$ are

$$
\begin{aligned}
& a \hat{g} \hat{z}^{a-1}+\hat{\lambda} a(a-1)(1-\hat{g}) \hat{z}{ }^{a-2}-\hat{\lambda} \hat{g} a \hat{z}^{a-1}-\hat{\lambda} \rho^{\prime}(\cdot) \\
& \quad \times\left[a(1-\hat{g}) \hat{z}^{a-1}-(a+1) \hat{g} \hat{z}^{a}\right]=0, \\
& \quad \hat{z}^{a}-a \hat{\lambda} \hat{z}^{a-1}-\hat{\lambda} \hat{z}^{a}+\hat{\lambda} \rho^{\prime}(\cdot)\left(\hat{z}^{a}+\hat{z}^{a+1}\right)=0,
\end{aligned}
$$

where $\hat{\lambda}$ is the associated Lagrange multiplier, $\hat{z}$ is the growth-maximizing privateto-public capital ratio, and $\hat{g}$ is the growth-maximizing government share in output. Solving (16) for $\hat{\lambda}$ and substituting in (15), we can obtain the following growthmaximizing policy rules.

PROPOSITION 1. Under endogenous time preference with respect to public capital, the growth-maximizing government share in output is different from the elasticity of public capital in the production function and is given by

$$
\begin{gathered}
\hat{g}=\frac{a\left[1-a+\rho^{\prime}(\cdot) \hat{z}\right]}{a+\rho^{\prime}(\cdot) \hat{z}^{2}}>0, \\
a(1-\hat{g}) \hat{z}^{a-1}-\hat{g} \hat{z}^{a}-\rho[\omega(\hat{z}) \hat{z}]=0 .
\end{gathered}
$$

Proof. See the Appendix. 
TABLE 1. Changes in $b$ and growthmaximizing allocation

\begin{tabular}{lccccc}
\hline$b$ & $\phi$ & $\hat{g}$ & $\hat{z}$ & $\hat{\omega}$ & $\hat{\rho}$ \\
\hline 0.2 & 0.312 & 0.545 & 0.382 & 0.400 & 0.031 \\
0.4 & 0.298 & 0.579 & 0.310 & 0.432 & 0.055 \\
0.6 & 0.285 & 0.607 & 0.262 & 0.456 & 0.072 \\
1 & 0.266 & 0.649 & 0.201 & 0.491 & 0.100 \\
1.4 & 0.251 & 0.679 & 0.165 & 0.515 & 0.120 \\
1.8 & 0.238 & 0.702 & 0.140 & 0.533 & 0.135 \\
10 & 0.138 & 0.847 & 0.037 & 0.634 & 0.235 \\
\hline
\end{tabular}

Notes: $a=0.5, \delta=0.025, \check{\rho}=0.001$.

Proposition 1 yields the growth-maximizing government size, $\hat{g}$, as a function of parameters through the system of equations (17) and (18) with two unknowns, $\hat{z}$ and $\hat{g}$. It can be easily verified that when the rate of time preference is constant $\left[\rho^{\prime}(\cdot)=0\right]$, the government share in output should equal the elasticity of publicly provided public capital in the production function $(1-a)$, as in Barro (1990). However, for endogenous time preference with respect to public policy, the growthmaximizing government size does not depend only on the parameters of the production technology as in Barro (1990), Futagami et al. (1993), and Glomm and Ravikumar (1997), but also on demand-driven parameters.

The main mechanism that drives the result of Proposition 1 is that the endogeneity, of time preference changes the marginal cost of public funds. An increase in $\hat{g}$ not only affects growth by increasing public capital expenditures and decreasing private capital, but also impacts the steady-state rate of time preference, which through the Euler equation directly affects the growth rate and thus the tax base. So public policies implemented on the basis of the technology parameters of the economy become suboptimal when time preference is determined by fiscal policy.

Due to the complexity of the system, and without loss of generality, we adopt a linear specification of the impatience function as in Meng (2006) and present numerical results in order to analyze the sensitivity of growth-maximizing fiscal policy to the endogeneity of time preference. In particular, we introduce a linear impatience function given by $\rho\left(K / K_{g}\right)=b C / K_{g}+\check{\rho}$, where $b>0$ denotes the slope of the impatience function and measures the response of the rate of time preference to the ratio of aggregate consumption to public capital. ${ }^{9}$ Our aim is first to investigate how the sensitivity of time preference affects the growth rate and the optimal government size, $\hat{g}$. Next, we analyze the response of the growth rate and fiscal policy following a change of the public capital intensity in the production function to allow comparisons with standard literature.

Table 1 gives the response of the optimal government size, the growth rate, and other endogenous variables following a change in $b$. Verifying Proposition 1 , the growth-maximizing government size is higher than the elasticity of public 
capital in production, $1-a$, because the increase in government size not only affects growth through the share of tax-financed public capital in production but also impacts growth by increasing the rate of time preference. Thus, in order for the marginal benefit of public funds to equal their cost, the optimal government share, $\hat{g}$, has to be higher than $1-a$. An increase in $b$ leads to an increase in $\hat{g}$ and the rate of time preference, and to a decrease in the growth rate and in the private-to-public capital ratio. Intuitively, an increase in the slope of the impatience function increases ceteris paribus the rate of time preference, which lowers savings and capital accumulation and in turn decreases the private-to-public capital ratio. Also, by the Euler equation, an increase in the rate of time preference lowers the growth rate and the tax base of the economy, and thus requires an endogenous increase in $\hat{g}$ to finance public expenditures at the BGP.

Table 2 provides the response of the growth rate, the growth-maximizing government size, and other endogenous variables to increases in public capital elasticity for different values of $b$. For comparison purposes, the upper panel of Table 2 presents the results for the case of exogenous time preference, in which the growth-maximizing government size equals the elasticity of public capital in the production function. As the elasticity of public capital increases, public capital becomes more productive and it is optimal to allocate resources to public capital formation, which in turn lowers the ratio of private to public capital, $z$ [see Table 2, column (4)]. By the Euler equation (8), as $z$ decreases, the market interest rate increases and, thus, the growth rate increases. On the other hand, the marginal cost of public capital funds increases due to the decline in private savings and, as in Barro (1990), the optimal government size increases monotonically [see Table 2, column (3)]. The rise in government size lowers the after-tax market interest rate and the growth rate falls. Thus, the effect on the maximized growth rate is ambiguous when the rate of time preference is exogenous. For instance, when the elasticity of public capital is low, the private capital stock is relatively more productive and the negative growth effect from the decline in private savings is higher than the positive growth effect from the increase in public capital. Hence, under constant time preference, the optimal government size always increases following a rise in the elasticity of public capital in production, whereas the maximized growth rate exhibits a U-shaped pattern.

The middle and lower panels of Table 2 present the results when the rate of time preference is endogenized for relatively low and high time preference elasticities, $b=1$ and 10, respectively. In contrast to previous analysis, an increase in public capital intensity increases the growth rate of the economy for any value of $b$, whereas the effect on the growth-maximizing government size, $\hat{g}$, is not always monotonic. In particular, as public capital intensity increases, the allocation of resources to public capital formation rises and the rate of time preference falls, thus triggering an additional increase in the growth rate. Regarding the response of the optimal government size, for a relatively low value of the elasticity-of-time preference function $(b=1)$, the positive effect of the rise in public capital intensity on $\hat{g}$ is preserved because the additional marginal benefit from the increase in the 
TABLE 2. Changes in $1-a$ and growthmaximizing allocation

\begin{tabular}{lccccc}
\hline $1-a$ & $\phi$ & $\hat{g}$ & $\hat{z}$ & $\hat{\omega}$ & $\hat{\rho}$ \\
\hline \multicolumn{5}{c}{$b=0$ (exogenous time preference) } \\
0.2 & 0.481 & 0.2 & 3.193 & 0.127 & 0.001 \\
0.3 & 0.397 & 0.3 & 1.629 & 0.182 & 0.001 \\
0.4 & 0.349 & 0.4 & 0.897 & 0.251 & 0.001 \\
0.5 & 0.328 & 0.5 & 0.498 & 0.355 & 0.001 \\
0.6 & 0.329 & 0.6 & 0.265 & 0.532 & 0.001 \\
0.7 & 0.353 & 0.7 & 0.128 & 0.885 & 0.001 \\
0.8 & 0.414 & 0.8 & 0.049 & 1.76 & 0.001 \\
\multicolumn{7}{c}{} \\
0.2 & 0.287 & 0.535 & 0.509 & 0.218 & 0.112 \\
0.3 & 0.266 & 0.566 & 0.388 & 0.284 & 0.111 \\
0.4 & 0.260 & 0.603 & 0.286 & 0.367 & 0.106 \\
0.5 & 0.266 & 0.648 & 0.201 & 0.491 & 0.099 \\
0.6 & 0.286 & 0.701 & 0.131 & 0.698 & 0.092 \\
0.7 & 0.326 & 0.761 & 0.075 & 1.101 & 0.084 \\
0.8 & 0.399 & 0.829 & 0.034 & 2.063 & 0.073 \\
\multicolumn{7}{c}{$b$} & $b=10$ & & \\
0.2 & 0.073 & 0.836 & 0.068 & 0.180 & 0.125 \\
0.3 & 0.087 & 0.834 & 0.057 & 0.276 & 0.159 \\
0.4 & 0.108 & 0.838 & 0.046 & 0.416 & 0.196 \\
0.5 & 0.137 & 0.846 & 0.036 & 0.633 & 0.235 \\
0.6 & 0.179 & 0.859 & 0.027 & 1.00 & 0.271 \\
0.7 & 0.242 & 0.878 & 0.018 & 1.69 & 0.277 \\
0.8 & 0.340 & 0.903 & 0.010 & 3.22 & 0.351 \\
\hline
\end{tabular}

Notes: $\delta=0.025, \check{\rho}=0.001$.

growth rate cannot outweigh the induced increase in the marginal cost. However, for high responsiveness of time preference $(b=10)$ and for sufficiently low values of $1-a$ (ranging between 0.2 and 0.4 ), the increasing marginal cost of public funds is outweighed by the increase in the growth rate and the tax base of the economy. Hence, when $b$ is high, an increase in public capital intensity that increases public capital lowers the rate of time preference to a great extent. This, in turn, fuels growth and increases the tax base, and a smaller government size is required to finance public capital expenditures. Moreover, when $1-a$ is relatively low, the public capital stock is relatively scarce and its marginal value is high. A rise in $1-a$ therefore induces a smaller increase in its marginal cost, and the required increase in the optimal government size is low. Thus, in economies where the rate of time preference responds strongly to changes in the public capital stock and the elasticity of public capital in the production function is low, the government 
can benefit from the additional effect on growth and impose a lower optimal government size following a rise in the elasticity of public capital.

\section{CONCLUDING REMARKS}

This paper studied the macroeconomic implications of the endogeneity of time preference with respect to publicly provided capital stock. We examined the steadystate dynamics of the economy and analyzed the impact of growth-maximizing fiscal policy. We showed that the growth-maximizing government size depends on the endogeneity of time preference, as the marginal cost of government revenues decreases due to the positive external effect of public capital on the rate of time preference and growth. Our comparative statics exercises regarding standard parameters of growth theory challenge the standard fiscal policy rules in the growth literature and show that their qualitative properties depend on the effect of public policy on time preference. As shown in our numerical results, the government does not necessarily have to increase income taxation following a rise in the output elasticity of public capital because of the external effect of public capital on time preference and, in turn, on growth and the tax base of the economy.

In this vein, the empirical assessment of the magnitude of the linkage between individual time preference and the social level of health and education seems an important task for future research. Existing studies that have investigated the determinants of time preference empirically at the country level, surveyed by Becker and Mulligan (1997), normally indicate that wealth, which is higher in healthier and more educated societies, is positively associated with patience. However, there is no cross-country evidence on the magnitude of time preference or its association with public policies. It appears therefore that further empirical analysis of the determinants of the rate of time preference, which will take into account the role of aggregate health status and education, is warranted.

Our analysis has treated public expenditures on health and education in a unified manner. Yet, as shown, for instance, by Blankenau and Simpson (2004), expenditures on public education can have adverse effects on growth due to general equilibrium adjustments. Similarly, Aisa and Pueyo (2006) have shown that an intense positive effect of public health expenditure on life expectancy, saving, and growth could offset the effect of taking away resources from investment. Future work on the endogeneity of time preference with respect to public policy can therefore address the macroeconomic impact of investment reallocation between sectoral public expenditures, as well as the corresponding effects of differential forms of taxation.

\section{NOTES}

1. Fuchs (1982) first provided empirical evidence on the links between time preference, health status, and schooling. Other studies by Shoda et al. (1990), Olsen (1993), van der Pol and Cairns (2000), Lazaro et al. (2001), Kirby et al. (2002), Khwaja et al. (2007), Asenso-Boadi et al. (2008), and Chao et al. (2009) have also reported that education and health affect patience. 
2. Regarding health, Chakraborty (2004) and Hashimoto and Tabata (2005) provide evidence on the impact of public health expenditures on individual time horizons and analyze their effects in overlapping-generations models.

3. Throughout the rest of the paper, the time subscript $t$ is omitted for simplicity of notation.

4. We retain the equality sign in our assumptions to allow, first, comparisons with the case of constant rate of time preference and, second, the impatience function to be consistent with a balanced growth path, along which the time preference is constant.

5. Agenor $(2006,2008)$ adopts a similar assumption in order to study the optimal allocation of public expenditures. Notice that this effect has also been embodied in some overlapping-generations models with endogenous longevity or mortality through the impact of health expenditures on the expected individual lifespan; see, for instance, Chakraborty (2004) and Bhattacharya and Qiao (2007).

6. We thank a referee for pointing out the connection between variable time preference and commitment.

7. This result can easily be obtained by investigating the equilibrium growth rates of these variables separately. In particular, for the steady-state consumption growth rate, given by (8), to be constant both $K$ and $K_{g}$ have to grow at the same constant rate, say $\phi_{K}^{\mathrm{CDE}}=\phi_{K_{g}}^{\mathrm{CDE}}=\phi^{\mathrm{CDE}}$. Because the steady-state ratio of private to public capital will be constant, the equilibrium growth rate of consumption, $\phi_{C}^{\mathrm{CDE}}$, will be constant too. Thus, by inspection of (9), for the growth rate of physical capital to be constant we need that $\phi_{K}^{\mathrm{CDE}}=\phi_{K_{g}}^{\mathrm{CDE}}$ and $\phi_{C}^{\mathrm{CDE}}=\phi_{K}^{\mathrm{CDE}}$ (for $K / K_{g}$ and $C / K$ to be constant, respectively). These conditions imply that $\phi_{C}^{\mathrm{CDE}}=\phi_{K}^{\mathrm{CDE}}=\phi_{K_{g}}^{\mathrm{CDE}}=\phi^{\mathrm{CDE}}$, which also satisfies (10) as well as the transversality condition (11).

8. Lau (1995), Greiner and Hanusch (1998), Economides et al. (2007), and Misch et al. (2008) have analyzed the welfare and growth effects of fiscal policy in endogenous growth models. Mourmouras and Lee (1999) and Tanaka (2002) have examined the growth-maximizing effects of government spending on infrastructure in an OLG setup.

9. Notice that the qualitative results presented below are not sensitive to the assumption of a linear time preference function.

\section{REFERENCES}

Agenor, Pierre-Richard (2006) A Theory of Infrastructure-Led Development. Discussion Paper EDP0640, University of Manchester.

Agenor, Pierre-Richard (2008) Health and infrastructure in a model of endogenous growth. Journal of Macroeconomics 30, 1407-1422.

Aisa, Rosa and Fernando Pueyo (2006) Government health spending and growth in a model of endogenous longevity. Economics Letters 90, 249-253.

Asenso-Boadi, Francis, Tim J. Peters, and Joanna Coast (2008) Exploring differences in empirical time preference rates for health: An application of meta-regression. Health Economics 17, 235248.

Barro, Robert J. (1990) Government spending in a simple model of endogenous growth. Journal of Political Economy 98, 103-125.

Barro, Robert J. (1999) Ramsey meets Laibson in the neoclassical growth model. Quarterly Journal of Economics 114, 1125-1152.

Bauer, Michal and Julie Chytilova (2010). The impact of education on subjective discount rate in Ugandan villages. Economic Development and Cultural Change 58, 643-669.

Becker, Gary S. and Casey B. Mulligan (1997) The endogenous determination of time preference. Quarterly Journal of Economics 112, 729-758.

Bhattacharya, Joydeep and Xue Qiao (2007) Public and private expenditures on health in a growth model. Journal of Economic Dynamics and Control 31, 2519-2535.

Blankenau, William F. and Nicole B. Simpson (2004) Public education expenditures and growth. Journal of Development Economics 73, 583-605. 
Chakraborty, Shankha (2004) Endogenous lifetime and economic growth. Journal of Economic Theory 116, 119-136.

Chao, Li-Wei, Helena Szrek, Nuno Sousa Pereira, and Mark V. Pauly (2009) Time preference and its relationship with age, health, and survival probability. Judgment and Decision Making 4, 119.

Chen, Been-Lon (2007) Multiple bgps in a growth model with habit persistence. Journal of Money, Credit and Banking 39, 25-48.

Devarajan, Shantayanan, Vinaya Swaroop, and Heng-fu Zou (1996) The composition of public expenditure and economic growth. Journal of Monetary Economics 37, 313-344.

Dolmas, Jim (1996) Balanced-growth-consistent recursive utility. Journal of Economic Dynamics and Control 20, 657-680.

Drugeon, Jean-Pierre (1996) Impatience and long-run growth. Journal of Economic Dynamics and Control 20, 281-313.

Drugeon, Jean-Pierre (2000) On the roles of impatience in homothetic growth paths. Economic Theory $15,139-161$.

Economides, George, Hyun Park, and Apostolis Philippopoulos (2007) Optimal protection of property rights in a general equilibrium model of growth. Scandinavian Journal of Economics 109, 153175.

Epstein, Larry G. and J. Allan Hynes (1983) The rate of time preference and dynamic economic analysis. Journal of Political Economy 91, 611-635.

Fuchs, Victor R. (1982) Time preference and health: An exploratory study. In Victor R. Fuchs (ed.), Economic Aspects of Health, pp. 93-120. Chicago: University of Chicago Press.

Futagami, Koichi, Yuichi Morita, and Akihisa Shibata (1993) Dynamic analysis of an endogenous growth model with public capital. Scandinavian Journal of Economics 95, 607-625.

Glomm, Gerhard and B. Ravikumar (1997) Productive government expenditures and long-run growth. Journal of Economic Dynamics and Control 21, 183-204.

Glomm, Gerhard and B. Ravikumar (1998) Flat-rate taxes, government spending on education, and growth. Review of Economic Dynamics 1, 306-325.

Greiner, Alfred and Horst Hanusch (1998) Growth and welfare effects of fiscal policy in an endogenous growth model with public investment. International Tax and Public Finance 5, 249-261.

Harrison, Glenn W., Morten I. Lau, and Melonie B. Williams (2002) Estimating individual discount rates in Denmark: A field experiment. American Economic Review 92, 1606-1617.

Hashimoto, Ken-ichi and Ken Tabata (2005) Health infrastructure, demographic transition and growth. Review of Development Economics 9, 549-562.

Horioka, Charles Y. (1990) Why is Japan's households saving so high? A literature survey. Journal of the Japanese and International Economies 4, 49-92.

Khwaja, Ahmed, Dan Silverman, and Frank Sloan (2007) Time preference, time discounting, and smoking decisions. Journal of Health Economics 26, 927-949.

Kirby, Kris N., Ricardo Godoy, Victoria Reyes-Garcia, Elizabeth Byron, Lilian Apaza, William Leonard, Eddy Perez, Vincent Vadez, and David Wilkie (2002) Correlates of delay-discount rates: Evidence from Tsimane' Amerindians of the Bolivian rain forest. Journal of Economic Psychology 23, 291-316.

Laibson, David (1997) Golden eggs and hyperbolic discounting. Quarterly Journal of Economics 112, 443-477.

Lau, Sau-Him Paul (1995) Welfare-maximizing vs. growth-maximizing shares of government investment and consumption. Economics Letters 47, 351-359.

Lawrance, Emily C. (1991) Poverty and the rate of time preference: Evidence from panel data. Journal of Political Economy 99, 54-77.

Lazaro, Angelina, Ramon Barber, and Encarnacion Rubio (2001) Private and social time preferences for health and money: An empirical investigation. Health Economics 10, 351-356.

Meng, Qinglai (2006) Impatience and equilibrium indeterminacy. Journal of Economic Dynamics and Control 30, 2671-2692. 
Misch, Florian, Norman Gemmell, and Richard Kneller (2008) Growth and Welfare Maximization in Models of Public Finance and Endogenous Growth. CREDIT Research Paper 08/09, University of Nottingham.

Mourmouras, Iannis A. and Jong Eun Lee (1999) Government spending on infrastructure in an endogenous growth model with finite horizons. Journal of Economics and Business 51, 395-407.

Obstfeld, Maurice (1990) Intertemporal dependence, impatience and dynamics. Journal of Monetary Economics 26, 45-75.

Olsen, Jan Abel (1993) Time preferences for health gains: An empirical investigation. Health Economics 2, 257-265.

Palivos, Theodor, Ping Wang, and Jianbo Zhang (1997) On the existence of balanced growth equilibrium. International Economic Review 38, 205-224.

Sheldon, Garon (1997) Molding Japanese Minds: The State in Everyday Life. Princeton, NJ: Princeton University Press.

Sheldon, Garon (1998) Fashioning a culture of diligence and thrift: Savings and frugality campaigns in Japan, 1900-1931. In Sharon Minichiello (ed.), Japan's Competing Modernities: Issues in Culture and Democracy, 1900-1930, pp. 312-334. Honolulu: University of Hawaii Press.

Shin, Shouyong and Larry G. Epstein (1993) Habits and time preference. International Economic Review 34, 61-84.

Shoda, Yuichi, Walter Mischel, and Philip K. Peake (1990) Predicting adolescent cognitive and selfregulatory competencies from preschool delay of gratification: Identifying diagnostic conditions. Developmental Psychology 26, 978-986.

Stern, Michael L. (2006) Endogenous time preference and optimal growth. Economic Theory 29, 49-70.

Strauss, John and Duncan Thomas (1998) Health, nutrition, and economic development. Journal of Economic Literature 36, 766-817.

Strotz, Robert H. (1956) Myopia and inconsistency in dynamic utility maximization. Review of Economic Studies 23, 165-180.

Tanaka, Jumpei (2002) A note on government spending on infrastructure in an endogenous growth model with finite horizon. Economics Letters 54, 651-653.

Turnovsky, Stephen J. (2000) Methods of Macroeconomic Dynamics, 2nd ed. Cambridge, MA: MIT Press.

Uzawa, Hirofumi (1968) Time preference, the consumption function, and optimal asset holdings. In John N. Wolfe (ed.), Value, Capital and Growth: Papers in Honour of Sir John Hicks, pp. 485-504. Edinburgh: Edinburgh University Press.

Van der Pol, Marjon M. and John A. Cairns (2000) Zero and negative time preference for health. Health Economics 9, 171-175.

\section{APPENDIX: PROOFS OF EQUATION (14) AND PROPOSITION 1}

Proof of (14). To prove the uniqueness of (14), we will separate function $\Phi(z)$ into two functions and find their intersection to solve it. We define $\Gamma(z) \equiv a(1-g) z^{a-1}-z^{a} g$ and $\Lambda(z) \equiv \rho[(z \cdot \omega(z))]$, which are both continuous in $z$. For $\omega(z)>0$ to hold we must have $z<(1-g) / g$.

Equation $\Gamma(z)$ has the following properties: $\partial \Gamma(z) / \partial z<0, \quad \partial^{2} \Gamma(z) / \partial z^{2}>0$, $\lim _{z \rightarrow 0} \Gamma(z)=+\infty, \lim _{z \rightarrow 1-g / g} \Gamma(z)=a(1-g)[(1-g) / g]^{a-1}-[(1-g) / g]^{a} g=$ $[(1-g) / g]^{a}[(1-g) a g /(1-g)-g]=[(1-g) / g]^{a} g(a-1)<0$. From the properties of $\Gamma(z)$ it follows that it is a strictly decreasing and convex function in its domain, starts from $+\infty$, and ends at $(a-1)(1-g)^{a} g^{1-a}$. 
Equation $\Lambda(z)$ has the following properties: $\partial \Lambda(z) / \partial z=\rho^{\prime}().\left[a(1-g) z^{a-1}-g(1+\right.$ a) $\left.z^{a}\right], \lim _{z \rightarrow 0} \Lambda(z)=\rho(0)=\check{\rho}, \lim _{z \rightarrow 1-g / g} \Lambda(z)=\rho(0)=\check{\rho}$. In turn, we have $\partial \Lambda(z) / \partial z>0$ for $a(1-g) z^{a-1}-(1+a) g z^{a}>0 \Rightarrow z<a(1-g) /(1+a) g$ and $\partial \Lambda(z) / \partial z<0$ for $z>a(1-g) /(1+a) g$. Thus, $\Lambda(z)$ has a maximum at $z=a(1-g) /(1+a) g$. From the properties of $\Lambda(z)$, it follows that it is an inverse U-shaped curve starting from $\check{\rho}$ and ending at $\check{\rho}$.

Assuming equilibrium existence, the properties of $\Lambda(z)$ and $\Gamma(z)$ indicate that there exists a unique equilibrium growth rate. For low values of $z$, because $+\infty>\check{\rho}$, we get that $\Gamma(z)$ lies above $\Lambda(z)$. Also, for the upper bound value of $z, \Gamma(z)=(a-1)(1-g)^{a} g^{1-a}$ and $\Lambda(z)=\check{\rho}$. Because both functions are continuous if $(a-1)(1-g)^{a} g^{1-a}<\check{\rho}$, which means that $\Gamma(z)$ ends below $\Lambda(z)$, because $\Gamma(z)$ starts above $\Lambda(z), \Gamma(z)$ will cross $\Lambda(z)$ once and thus there will exist a unique equilibrium growth rate. Thus, $(a-1)(1-g)^{a} g^{1-a}<\check{\rho}$ is a sufficient parametric condition for a unique equilibrium growth rate in the economy and exists for any parameter value in the assumed domain because $(a-1)<0 \Rightarrow$ $(a-1)(1-g)^{a} g^{1-a}<0<\check{\rho}$.

Proof of Proposition 1. We prove Proposition 1 by contradiction. From (17), let $\hat{g}=\left[a\left(1-a+\rho^{\prime}(\cdot) \hat{z}\right)\right] /\left[a+\rho^{\prime}(\cdot) \hat{z}^{2}\right]=1-a$. This holds if $a\left[1-a+\rho^{\prime}(\cdot) \hat{z}\right]=$ $(1-a)\left[a+\rho^{\prime}(\cdot) \hat{z}^{2}\right] \Rightarrow 1-a+\rho^{\prime}(\cdot) \hat{z}=1-a+[(1-a) / a] \rho^{\prime}(\cdot) \hat{z}^{2} \Rightarrow \rho^{\prime}(\cdot) \hat{z}=$ $[(1-a) / a] \rho^{\prime}(\cdot) \hat{z}^{2} \Rightarrow[(1-a) / a] \hat{z}=1 \Rightarrow \hat{z}=a /(1-a)$ (Condition 1). We know that for an interior solution to exist in the CDE we must have that $\hat{z}<(1-g) / g$. Thus, for $\hat{g}=1-a$, the condition for interior solution implies that $\hat{z}<a /(1-a)$, which contradicts Condition 1. 